\title{
Ninhydrin Inhibition of Glucose-Induced Insulin Release
}

\author{
M. L. McDaniel, C. E. Roth, C.J. Fink, J. A. Swanson, and P.E. Lacy \\ Department of Pathology, Washington University School of Medicine, St. Louis, Missouri, USA
}

Summary. Ninhydrin, a compound which shares chemical properties strikingly similar to alloxan was found to mimic basically the inhibitory effect of alloxan on glucose-induced insulin release. Exposure of pancreatic islets for five minutes to $85 \mu \mathrm{mol} / 1$ ninhydrin produced approximately ninety percent inhibition of subsequent glucose-induced insulin release without altering basal secretion. Both D-glucose and D-mannose provided substantial protection against the inhibitory effect of ninhydrin, and the alpha anomer of D-glucose was more effective than the beta anomer in preventing ninhydrin inhibition of insulin release. Evidence for a common site of inhibition by ninhydrin and alloxan in the insulin release process is discussed.

Key words: Ninhydrin, pancreatic islets, insulin release, alloxan, hexoses.

Alloxan has been established as a diabetogenic agent, in vivo, [1] and this diabetogenic action of alloxan is prevented by the prior administration of the hexoses; D-glucose, D-mannose, and 3-0methyl-D-glucose [2-5]. More recently, the protection provided by $\mathrm{D}$-glucose against the diabetogenic action of alloxan has demonstrated anomer preference with alpha $\mathrm{D}$-glucose providing more protection at lower concentrations than beta $\mathrm{D}$-glucose [6-7].

To relate the chemical properties of alloxan to its biological effect, early studies were directed at comparing the diabetogenic action of compounds similar in structure and chemical reactivity to alloxan. An agent of significant interest in these in vivo studies was ninhydrin, a compound which shares chemical properties strikingly similar to those of alloxan [8]. Both compounds (Fig. 1) possess a reactive moiety, i.e. a gem-diol adjacent to two carbonyl groups, demonstrate oxidative properties $[9,10]$, form addition products with the guanidino group of arginine [11], react with thiol groups by both oxidative and/or additive mechanisms [12], and mediate the Strecker reaction $[9,10]$. In early studies, ninhydrin was evaluated as a diabetogenic agent at concentrations comparable to those of alloxan. The administration of ninhydrin was accompanied by acute toxicity, and only occasional episodes of transitory hyperglycaemia were observed [13].

Recent in vitro studies demonstrated that exposure of isolated rat pancreatic islets to alloxan for five minutes inhibits subsequent glucose-induced insulin secretion $[14,15]$. The presence of a high concentration of either D-glucose, D-mannose, or 3-0methyl-D-glucose during this brief alloxan-exposure provided almost complete protection of the beta cells from the inhibitory effect of alloxan. The in vitro protection by $\mathrm{D}$-glucose against alloxan also shows anomer preference in that alpha D-glucose is more effective than beta D-glucose in preventing inhibition of insulin release $[14,16]$.

The purpose of the present investigation was to determine the in vitro effect of ninhydrin on glucose-induced insulin release in isolated islets of Langerhans. The effect of ninhydrin was determined
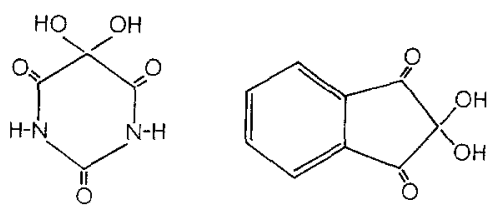

ALLOXAN

NINHYDRIN

Fig. 1. Chemical structures 
Table 1. Effect of ninhydrin concentration on subsequent glucose-induced insulin release

\begin{tabular}{ll}
\hline $\begin{array}{l}\text { Ninhydrin } \\
\text { concentration } \\
\mu \mathrm{mol} / 1\end{array}$ & \% Inhibition \\
\hline 10 & $24.3 \pm 1.5(12)$ \\
25 & $53.9 \pm 2.5(12)$ \\
65 & $74.2 \pm 1.7(11)$ \\
85 & $89.2 \pm 0.7(12)$ \\
\hline
\end{tabular}

Following a $15 \mathrm{~min}$ pre-incubation period, islets were exposed to ninhydrin at the designated concentration for $5 \mathrm{~min}$, the medium removed, and the islets were then incubated in medium containing $D$-glucose $(27.5 \mathrm{mmol} / \mathrm{l})$ for $30 \mathrm{~min}$. The average rate of glucose-induced insulin release in untreated islets was $3.58 \pm 0.28$ $(\mathrm{n}=24) \mu \mathrm{U} / \mathrm{islet} / \mathrm{min}$. The values represent the mean $\pm \mathrm{SEM}$ with the number of observations indicated in parenthesis

both in the absence and presence of hexoses under conditions which have been employed in the evaluation of alloxan.

\section{Methods}

Isolated pancreatic islets were obtained by collagenase digestion [17] from adult (200-300 g) male Wistar rats allowed food and water ad libitum. Static incubations were performed in a Krebs-Ringer bicarbonate (KRB) medium [16] containing crystallized bovine plasma albumin $(5 \mathrm{mg} / \mathrm{ml})$ and maintained at $\mathrm{pH} 7.4$ by equilibration with a mixture of $95 \% \mathrm{O}_{2}$ and $5 \% \mathrm{CO}_{2}$.

Following isolation, islets were transferred with the aid of a glass loop and dissection microscope to round-bottom vials $(11 \mathrm{~mm}$ dia $\times 20 \mathrm{~mm}$ height) which contained $200 \mu \mathrm{l}$ of KRB medium supplemented with $\mathrm{D}$-glucose $(5.5 \mathrm{mmol} / \mathrm{l})$. Each vial contained $20-25$ islets and $12-15$ vials were employed per experiment. The vials were placed in scintillation vials equipped with rubber stoppers for gassing and maintained at $37^{\circ} \mathrm{C}$ in a Dubnoff metabolic shaker (100 strokes/min) water bath. Removal and addition of medium $(200 \mu \mathrm{l})$ was accomplished with a constriction pipette.

The basic protocol consisted of a preincubation period of 15 minutes performed in a glucose-free medium. Following this preincubation period, the medium was removed and replaced with medium containing either ninhydrin alone or, in the protection studies, ninhydrin in the presence of a hexose for the five minute exposure period. The medium was then removed and replaced with medium containing D-glucose $(27.5 \mathrm{mmol} / 1)$ for a $30 \mathrm{~min}$ insulin stimulation period. Insulin release from islets exposed to ninhydrin alone or ninhydrin in the pres- ence of a hexose was compared to that of a parallel group of islets in which the ninhydrin exposure period was omitted. At the termination of the stimulation period, the medium was removed and frozen for insulin assay by the method of Wright et al. [18]. Results are expressed as $\mu U$ insulin/islet/minute, and percent protection was calculated from the following equation:

$\frac{(\text { rate stimulated release }- \text { basal rate }\{\text { Exp. }\})}{(\text { rate stimulated release }- \text { basal rate }\{\text { Control }\})} \times 100 \%$

Ninhydrin (triketohydrindene hydrate, Fischer Scientific) was prepared in distilled water and added to the KRB medium at the appropriate concentration just prior to use. Both the stability and final ninhydrin concentration were based on the U.V. spectrum at $232 \mathrm{~nm}, \mathrm{E}=3.4 \times 10^{4}$ litre: $\mathrm{mol}^{-1}$ $\mathrm{cm}^{-1}$, [10]. All hexoses were obtained from Sigma Chem. Co., St. Louis, Mo. with the exception of Dglucose, National Bureau of Standards, Washington, D. C., and D-allose, P and L Biochem., Milwaukee, Wisconsin. Alpha and beta D-glucose stock solutions were prepared $15 \mathrm{~min}$ prior to use and maintained on ice until added to the incubation medium.

\section{Results}

In initial studies, the in vitro effect of ninhydrin concentration on glucose-induced insulin release was determined. In this study (Table 1 ), the average rate of glucose-induced insulin release in control (nonninhydrin exposed) islets was $3.58 \pm 0.28 \mu \mathrm{U}$ per islet per minute $(n=24)$. A basal rate of insulin release determined over the preincubation period in a glucose-free medium was approximately $0.4 \mu \mathrm{U}$ per islet per minute. Exposure of islets to $25 \mu \mathrm{mol} / 1$ ninhydrin for 5 minutes produced $53.9 \%$ inhibition of subsequent glucose-induced insulin release which approximates the inhibitor $K_{1}$ of ninhydrin, i. e. the concentration producing one-half maximal inhibition. Exposure of islets to $85 \mu \mathrm{mol} / 1$ ninhydrin produced $89.2 \%$ inhibition of subsequent glucose-induced insulin release and did not affect basal insulin release. This concentration of ninhydrin $(85 \mu \mathrm{mol} / 1)$ was chosen for the subsequent evaluation of hexoses in preventing inhibition of glucose-induced insulin release by ninhydrin. In the dose response study, concentrations of ninhydrin greater than $85 \mu \mathrm{mol} / 1$ produced complete suppression of insulin release.

In the following experiments, the ability of eight hexoses to protect against the inhibitory effect of ninhydrin was determined. In this protocol, D-glucose was evaluated during the pulse period at a con- 
Table 2. Effect of protective agents on ninhydrin inhibition of insulin release

\begin{tabular}{|c|c|c|c|c|}
\hline \multirow{2}{*}{$\begin{array}{l}\text { Protective agent } \\
(27.5 \mathrm{mmol} / \mathrm{l})\end{array}$} & \multicolumn{4}{|c|}{ Insulin $\mu \mathrm{U} /$ islet $/$ minute } \\
\hline & Control & $\begin{array}{l}\text { Agent } \\
+ \text { ninhydrin }\end{array}$ & Ninhydrin & $\%$ Protection \\
\hline D-glucose & $3.29 \pm 0.20(16)$ & $2.46 \pm 0.20(16)$ & $0.71 \pm 0.08(15)$ & 68 \\
\hline D-mannose & $2.63 \pm 0.18(16)$ & $1.55 \pm 0.16(15)$ & $0.69 \pm 0.17(16)$ & 44 \\
\hline 3-0-M-glucose & $2.66 \pm 0.16(16)$ & $0.53 \pm 0.08(16)$ & $0.49 \pm 0.05(16)$ & 2 \\
\hline L-glucose & $2.95 \pm 0.47(15)$ & $0.50 \pm 0.10(15)$ & $\cdot$ & 0 \\
\hline D-fructose & $3.03 \pm 0.12(16)$ & $0.76 \pm 0.11(16)$ & $0.53 \pm 0.07(15)$ & 9 \\
\hline D-galactose & $2.70 \pm 0.19(16)$ & $0.51 \pm 0.07(16)$ & $0.43 \pm 0.06(16)$ & 4 \\
\hline D-allose & $3.07 \pm 0.22(15)$ & $0.54 \pm 0.13(16)$ & $0.56 \pm 0.14(16)$ & 0 \\
\hline 2-deoxy-D-glucose & $2.71 \pm 0.23(16)$ & $0.89 \pm 0.07(15)$ & $0.88 \pm 0.08(14)$ & 0 \\
\hline
\end{tabular}

Islets were exposed to ninhydrin $(85 \mu \mathrm{mol} / \mathrm{l})$ for five minutes in the absence and presence of a designated hexose $(27.5 \mathrm{mmol} / \mathrm{l})$, or the ninhydrin exposure was omitted (control). The medium was removed, and islets were then incubated in medium containing D-glucose $(27.5 \mathrm{mmol} / \mathrm{l})$ for $30 \mathrm{~min}$. The rate of insulin release from islets exposed to ninhydrin alone was equated to basal release in calculating percent protection. The values represent the mean \pm SEM with the number of observations in parenthesis

centration of $27.5 \mathrm{mmol} / \mathrm{l}$, which has been shown to provide almost complete protection against the in vitro effect of alloxan [14]. The remaining hexoses were evaluated at this same concentration. In these studies, three experimental conditions were employed during the five minute exposure interval: islets were exposed to ninhydrin $(85 \mu \mathrm{mol} / \mathrm{l})$ alone, exposed to ninhydrin in the presence of the indicated hexose, and the ninhydrin-exposure interval was omitted. As shown in Table 2, D-glucose and D-mannose were the only hexoses which provided significant protection against the inhibitory effect of ninhydrin. D-glucose provided 68 percent protection, whereas D-mannose provided 44 percent protection. The remaining hexoses: 3-0-methyl-D-glucose, L-glucose, D-fructose, D-allose, 2-deoxy-Dglucose and $\mathrm{D}$-galactose provided no detectable protection against the in vitro action of ninhydrin.

To evaluate further the in vitro inhibition of insulin release by ninhydrin, the relative protective effects of the anomers of D-glucose were examined. Islets were exposed to ninhydrin $(85 \mu \mathrm{mol} / \mathrm{l})$ for an exposure interval of five minutes in the presence of either alpha or beta $\mathrm{D}$-glucose. The relative protective effect of these anomers of D-glucose in preventing ninhydrin inhibition of insulin release was then determined. As indicated in Table 3, the presence of alpha D-glucose during the ninhydrin exposure interval resulted in a 56 percent increase in insulin release compared to beta D-glucose at anomer concentrations of $11 \mathrm{mmol} / \mathrm{l}$. When the anomer concentration was increased to $13.7 \mathrm{mmol} / \mathrm{l}$, the concomitant presence of alpha D-glucose and ninhydrin $(85 \mu \mathrm{mol} / \mathrm{l})$ resulted in a 95 percent increase in insulin release compared to beta $D$-glucose under identical conditions.
Table 3. Effect of anomers of D-glucose on ninhydrin inhibition of insulin release

\begin{tabular}{|c|c|c|}
\hline \multirow{2}{*}{$\begin{array}{l}\text { Anomer } \\
\text { conc. (mmol/l) }\end{array}$} & \multicolumn{2}{|c|}{ Insulin $\mu U /$ islet/minute } \\
\hline & $\begin{array}{l}\text { alpha D-glucose } \\
+ \text { ninhydrin }\end{array}$ & $\begin{array}{l}\text { beta D-glucose } \\
+ \text { ninhydrin }\end{array}$ \\
\hline 11.0 & $1.16 \pm 0.10(16)$ & $0.74 \pm 0.10$ \\
\hline 13.7 & $2.92 \pm 0.28(12)$ & $1.50 \pm 0.18(12)^{*}$ \\
\hline \multicolumn{3}{|c|}{$\begin{array}{l}\text { Islets were exposed to ninhydrin }(85 \mu \mathrm{mol} / \mathrm{l}) \text { for five minutes in } \\
\text { the presence of either alpha or beta } \mathrm{D} \text {-glucose at the designated } \\
\text { concentration. The medium was removed, and the islets were } \\
\text { then incubated in medium containing } \mathrm{D} \text {-glucose }(27.5 \mathrm{mmol} / \mathrm{l}) \\
\text { for } 30 \text { min. The values represent the mean } \pm \mathrm{SEM} \text { with the } \\
\text { number of observations indicated in parenthesis. } \\
* \mathrm{p}<0.001 \\
* * \mathrm{p}<0.01\end{array}$} \\
\hline
\end{tabular}

\section{Discussion}

These results indicate that ninhydrin at micromolar concentrations is very effective in inhibiting glucoseinduced insulin release in pancreatic islets. These results further suggest that in vivo evaluation of ninhydrin as a diabetogenic agent would require a detailed dose-response and that this dose response would most likely not parallel that of the more labile diabetogenic agent, alloxan. At physiological conditions of $\mathrm{pH} 7.4$ and a temperature of $37^{\circ} \mathrm{C}$, the $\mathrm{t}_{1 / 2}$ decomposition rate of alloxan is approximately one minute [19]. Although alloxan and ninhydrin share striking similarities in chemical reactivity due to an identical reactive moiety (Fig. 1), ninhydrin does not undergo the internal rearrangement responsible for the extreme lability of the alloxan molecule.

In this study, both D-glucose and D-mannose provided substantial protection (68 and 44 percent, 
respectively) against the inhibitory effect of ninhydrin. D-glucose and D-mannose have been shown to prevent the deleterious action of alloxan $[2-5,14$, $15]$ both in vivo and in vitro. On the basis of the protection afforded by these insulin secretagogues, a common site of inhibition by ninhydrin and alloxan is suggested.

Recent in vitro $[14,16]$ and in vivo $[6,7]$ studies have indicated a definite anomer specificity favouring alpha $\mathrm{D}$-glucose compared to beta $\mathrm{D}$-glucose in preventing alloxan inhibition of insulin release. In the present study, alpha D-glucose was significantly more effective in preventing inhibition of insulin release by ninhydrin than beta $\mathrm{D}$-glucose. It is of significance that in both in vivo and in vitro studies the insulinotrophic effect of $\mathrm{D}$-glucose demonstrates this same anomer specificity [16, 20-24]. The lack of significant protection by the hexoses: L-glucose, D-fructose, D-galactose, and 2-deoxy-D-glucose is also compatible with the small degree or absence of protection provided by these same hexoses in the presence of alloxan [15]. In addition, D-allose, the C-3 epimer of glucose, neither stimulates insulin release nor protects against alloxan in isolated islets (unpublished data), and does not protect against ninhydrin.

In the present study, 3-0-methyl-D-glucose provided no protection against the inhibitory effect of ninhydrin, whereas 3-0-methyl-D-glucose protects both in vivo and in vitro against the action of alloxan. Since 3-0-methyl-D-glucose provides protection against the inhibitory effect of alloxan, and not ninhydrin, the present findings suggest that 3-0methyl-D-glucose protects against alloxan by a mechanism different from that of the insulin secretagogues, D-glucose and D-mannose.

The present evidence which supports a common site of inhibition of insulin release by ninhydrin and alloxan are: 1) the similarity in chemical reactivity of the two compounds 2) protection by D-glucose and D-mannose against the biological effects of these agents and 3) the ability of the alpha anomer of D-glucose to prevent preferentially inhibition by these agents in comparison to the beta anomer. This evidence would suggest that inhibition by ninhydrin and alloxan is produced at a common site in the insulin release process.

Acknowledgement This research was supported in part by $\mathrm{NIH}$ grants AM01226, AM06181 and AM03373.

\section{References}

1. Dunn, J. S., Sheehan, H. L, McLetchie, N.G.B.. Necrosis of islets of Langerhans produced experimentally Lancet $\mathbf{2 4 4}$, 484-487 (1943)

2 Bhattacharya, G: Protection agannst alloxan diabetes by mannose and fructose Science 117, 230-231 (1953)

3 Bhattacharya, G.: On the protection against alloxan diabetes by hexoses. Science 120, 841-843 (1954)
4. Carter, W.J., Younathan, E. S.. Studies on protection against the diabetogenic effect of alloxan by glucose Exp. B1ol. Med. 109, 611-612 (1962)

5. Zawalich, W.S., Beidler, L.M.: Glucose and alloxan interactions in the pancreatic islets. Am. J. Physiol. 224, 963-966 (1973)

6. Rossini, A. A., Arcangeli, M. A., Cahill, Jr., G. F.: Studies of alloxan toxicity on the beta cell. Diabetes 24, 516-522 (1975)

7. Rossini, A. A., Berger, M., Shadden, J., Cahill, Jr., G.F.: Beta cell protection to alloxan necrosis by anomers of D-glucose. Science 183, 424 (1974)

8 McCaldin, D.J.: The chemistry of ninhydrin. Chem. Rev. 60, 39-51 (1960)

9. Rerup, C.: Drugs producing diabetes through damage of the insulin secreting cells. Pharmacol. Rev. 22, 485-517 (1970)

10. Webb, J. L.: Alloxan. In: J. Leyden Webb (ed.) Enzyme and metabolic inhibitors III, pp 367-419. New York: Academic Press 1966

11. Chaplin, M.: The use of ninhydrin as a reagent for the reversible modifivation of arginine residues in proteins. Biochem. J. 155, 457-459 (1976)

12. Younathan, E.S., Rudel, L. L.: Reaction of alloxan with thiol groups of proteins blockage of the reactivation of reduced ribonuclease. Biochim. Biophys. Acta 168, 11-15 (1968)

13. Hidy, P H.: Structural requirements for diabetogenic action in alloxan and related compounds. J. Biol. Chem. 163, 307-311 (1946)

14. Niki, A., Niki, H, Miwa, I., Lin, B.: Interaction of alloxan and anomers of D-glucose on glucose-induced insulin secretion and biosynthesis in vitro. Diabetes 25, 574-579 (1976)

15 Tomita, T., Lacy, P. E , Matschinsky, F M., McDaniel, M. L.: Effect of alloxan on insulin secretion on isolated rat islets perifused in vitro. Diabetes 23, 517-524 (1974)

16 McDaniel, M. L., Roth, C E., Fink, C. J., Lacy, P. E.. Effect of anomers of D-glucose on alloxan inhibition of insulin release in isolated perifused pancreatic islets. Endocrinology 99, 535-540 (1976)

17. Lacy, P.E., Kostianovsky, M . Method for the isolation of intact islets of Langerhans from the rat pancreas. Diabetes 16, 35-39 (1967)

18. Wright, P.H., Makulu, D.R., Vichick, D., Sussman, K.E.: Insulın immunoassay by back-titration; some characteristics of the technic and the insulin precipitant action of alcohol. Diabetes 20, 33-45 (1971)

19 McDaniel, M.L, Anderson, S., Fink, J., Roth, C., Lacy, P.E.: Effect of alloxan on permeability and hexose transport in rat pancreatic islets. Endocrinology 97, 68-75 (1975)

20. Rossini, A. A., Soeldner, J.S., Hielbert, J.M., We1r, G.C., Gleason, R.E. The effect of glucose anomers upon insulin and glucagon secretion. Diabetologia 10, 795-799 (1974)

21. Grodsky, G., Fanska, R., West, L, Manning, M.: Anomeric specificity of glucose-stımulated insulin release: evidence for a glucoreceptor? Science 186, 536-538 (1974)

22. Grodsky, G., Fanska, R., Lundquist, I.: Interrelationships between alpha and beta anomers of glucose affecting both insulin and glucagon secretion in the perfused rat pancreas II. Endocrinology 97, 573-580 (1975)

23. Nıki, A., Niki, H., Miwa, I , Okuda, J.. Insulin secretion by anomers of D-glucose. Science 186, 150-151 (1974)

24. Idahl, L., Sehlı, J., Taljedal, I. B : Metabolic and insulinreleasing activities of $\mathrm{D}$-glucose anomers. Nature 254, 75-77 (1975)

Recetved April 6, 1977, and in revised form $\cdot$ June 20, 1977

Dr. M.L. McDaniel

Department of Pathology

Washıngton University

School of Medicine

St Louis, MO 63110

USA 